\title{
Cytological and Molecular Characterization of Quantitative Trait Locus qRfg1, Which Confers Resistance to Gibberella Stalk Rot in Maize
}

\author{
Jianrong Ye, Yanling Guo, Dongfeng Zhang, Nan Zhang, Chao Wang, and Mingliang Xu \\ National Maize Improvement Center of China, China Agricultural University, 2 West Yuanmingyuan Road, Beijing 100193, \\ P.R. China; and Beijing Key Laboratory of Crop Genetic Improvement, China Agricultural University, 2 West Yuanmingyuan \\ Road, Beijing 100193, P. R. China
}

Submitted 23 April 2013. Accepted 23 July 2013.

Tremendous progress has been made recently in understanding plant response to Fusarium graminearum infection. Here, the cytological aspect and molecular mechanism of maize defense to $F$. graminearum infection were characterized using a pair of near-isogenic lines (NIL), the resistant and the susceptible NIL. $F$. graminearum primarily penetrated the maize root tip and no penetration structure was found. The fungal biomass within the root correlated well with root-disease severity. Following inoculation, R-NIL and S-NIL plants significantly differed in percentage of diseased primary roots. In R-NIL roots, a fraction of exodermal cells collapsed to form cavities, and hyphae were confined to the outer exodermal cells. However, most exodermal cells shrank and turned brown, and fungi colonized the entire S-NIL root. In the R-NIL roots, the exodermal cells exhibited plasmolysis and atropous hyphal growth whereas, in the exodermal cells of the S-NIL roots, severe cellular degradation and membrane-coated, lushly grown hyphae were found. Transcriptome sequencing revealed comprehensive transcription reprogramming, reinforcement of a complex defense network, to enhance the systemic and basal resistance. This study reports a detailed microscopic analysis of $\boldsymbol{F}$. graminearum infection on maize root, and provides insights into the molecular mechanisms underlying maize resistance to the pathogen.

The fungus Fusarium graminearum is a major global cereal pathogen. It causes Fusarium head blight (FHB) in wheat and barley (McMullen et al. 1997; Parry et al. 1995), crown rot in wheat (Stephens et al. 2008), stalk rot (Yang et al. 2010) in maize, and root rot (Henkes et al. 2011; Lanoue et al. 2010) in barley. This dramatically reduces both grain yield and quality. When $F$. graminearum infects wheat floral tissues, its biotrophic phase is followed by hyphal growth within intercellular spaces, intracellular colonization, cell death, and necrosis, which is similar to necrotrophic lifestyle (Brown et al. 2010; Trail 2009). Therefore, $F$. graminearum has been defined as a hemibiotrophic pathogen with an initial infection period that is

Corresponding author: M. Xu; Telephone: +86-10-62733116; Fax: +8610-62733808; E-mail: mxu@ cau.edu.cn

* The $\boldsymbol{e}$-Xtra logo stands for "electronic extra" and indicates that four supplementary tables and two supplementary figures are published online and that Figures 3 appears in color online.

(C) 2013 The American Phytopathological Society relatively long and symptomless followed by a rapid increase in fungal biomass and massive tissue necrosis in the end (Stephens et al. 2008).

$F$. graminearum macroconidia overwinter in the soil or on plant debris (Kazan et al. 2012). Its infection cycle begins with macroconidia germination, initial penetration and colonization, extensive colonization, and spread throughout the infected tissues. Lobate appressoria and infection cushions were observed during $F$. graminearum infection on florets (Boenisch and Schäfer 2011). Appressoria are essential for the penetration of the host cell wall, because they prepare for the transition from extracellular to an invasive life style. Bulbous infection hyphae were observed on detached wheat glumes. The deficiency of trichothecene production in the TRIS mutant did not affect the formation of these infection structures (Boenisch and Schäfer 2011), suggesting that these toxins are not necessary for the initial infection. To date, no detailed microscopic study has been reported on $F$. graminearum infection of maize roots, although the microscopic analysis of $F$. culmorum infection on wheat root was conducted, in which a rapid necrosis occurred within a few days after inoculation (Beccari et al. 2011). Both cell-wall-degrading enzymes (CWDE) and the trichothecene mycotoxin deoxynivalenol (DON) are the best known virulence factors (Kikot et al. 2009). Fungal genes encoding CWDE have been detected in various pathogenic processes (Güldener et al. 2006; Kang and Buchenauer 2000). Recently, 134 CWDE-encoding genes were reported to preferentially express during invasive growth of $F$. graminearum in wheat coleoptiles (Zhang et al. 2012). DON, acting as an inhibitor of eukaryote protein synthesis in vitro, may inhibit protein synthesis and increase virulence in vivo (Pestka 2010). Both programmed cell death (PCD) and enhanced defense gene expression were triggered with exogenous DON (Desmond et al. 2008; Nishiuchi et al. 2006). Exogenous application of DON facilitates $F$. graminearum infection (Chen et al. 2006). DON binds to and interferes with the protein synthesis apparatus, the cellular eukaryotic ribosomes (Pestka 2010). Low $\mathrm{pH}$ in culture medium, reactive oxygen species (ROS), various polyamines, ferulic acid, and coumaric acid promote DON biosynthesis in $F$. graminearum (Gardiner et al. 2009; Ponts et al. 2011). Higher levels of cinnamic acid and ferulic acid were observed in resistant wheat compared with susceptible genotypes (Hamzehzarghani et al. 2005, 2008). In addition to an induction of toxin biosynthesis, these defensive metabolites show antifungal activity against $F$. graminearum (Bollina et al. 2010; Ponts et al. 2011). Due to its toxicity to plant cells, DON triggers strong expression of genes involved in DON detoxification, such as genes encoding 
ABC transporters, uridine 5'-diphosphate (UDP)-glucosyltransferase, cytochrome $\mathrm{P} 450$ enzymes, and glutathione- $S$ transferases (Gardiner et al. 2010; Li et al. 2010).

According to previous reports, pathogenesis-related (PR) proteins, defense-related hormones, ROS, and proteins involved in cellular detoxification are produced by plants to counterattack $F$. graminearum infection. Some of these responses help to restrict $F$. graminearum infection and others would be exploited by the pathogen to aid pathogenicity. The defense regulator salicylic acid (SA) was critical for resistance in wheat (Makandar et al. 2010). Studies indicate that the jasmonic acid (JA) pathway mediates disease susceptibility (Ding et al. 2011; Makandar et al. 2010; Schreiber et al. 2011). Similarly, the ethylene (ET) signal pathway is also exploited by $F$. graminearum to cause disease (Chen et al. 2009; Thatcher et al. 2009). One reason for the susceptibility to $F$. graminearum provided by JA and ET pathways may be the involvement of these pathways in pathogen-induced senescence responses (Thatcher et
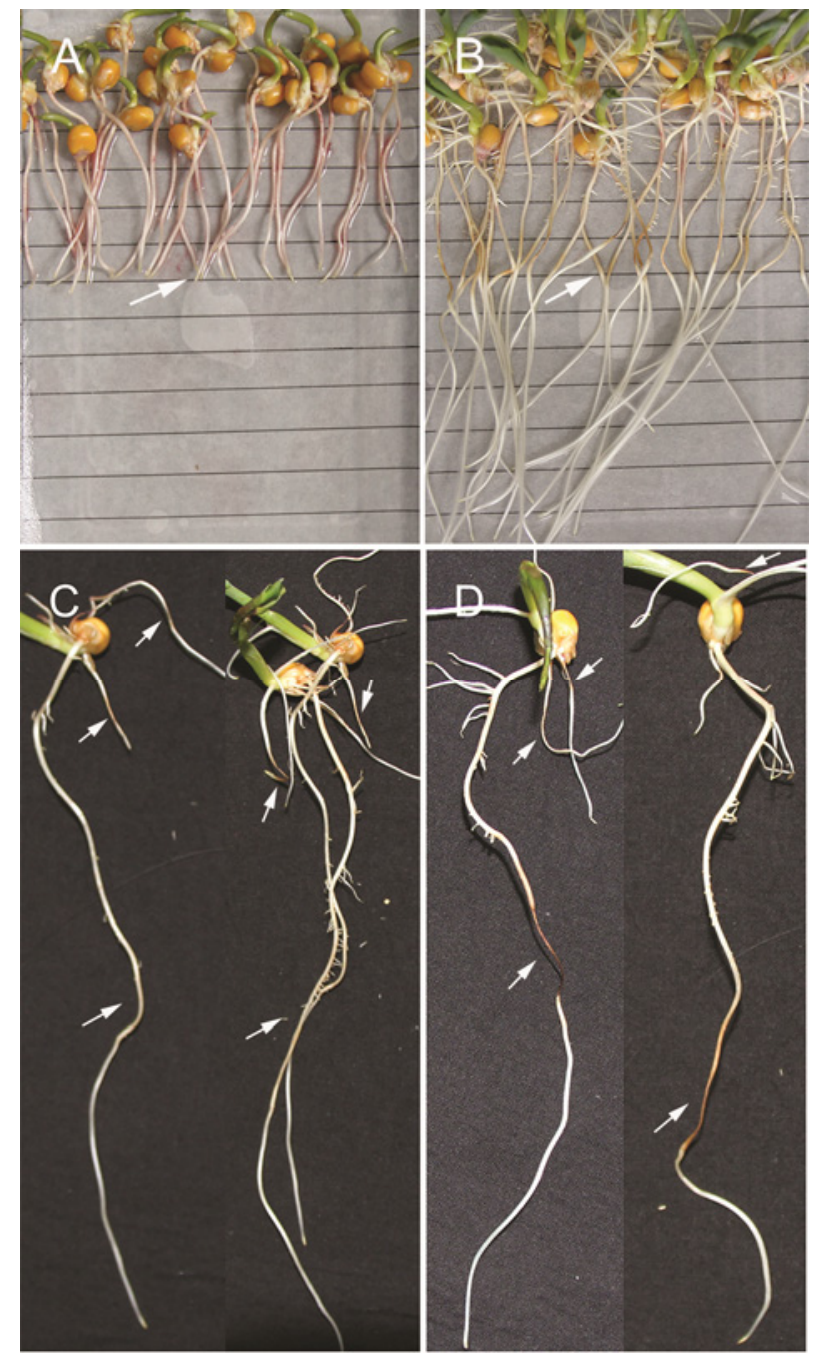

Fig. 1. Disease phenotypes associated with maize roots that carry either the resistant or susceptible $q R f g 1$ allele. A, At the time of Fusarium graminearum inoculation, the resistant near-isogenic line (R-NIL) plants had primary roots without any lateral roots. Arrow indicates root tips. B, Inoculated R-NIL roots at $48 \mathrm{~h}$ after inoculation (hai). Arrow indicates mild lesions that developed in the middle part of each root, which corresponded to the root tip at the time of inoculation. C, At 48 hai, the middle part of R-NIL roots displayed light-brown lesions that were not shrunken. D, At 48 hai, the susceptible NIL exhibited lesions in the middle region of the root that were shrunken and dark brown (severe lesions). Arrows in $\mathrm{C}$ and $\mathrm{D}$ indicate primary and lateral root regions that displayed disease symptoms. al. 2009). In contrast, another study suggests that the JA pathway is the predominant defense signal pathway against $F$. graminearum in barley (Kumaraswamy et al. 2011). Recent transgenic studies have shown that an antifungal plant defensin 2 (Li et al. 2011), a class II chitinase from barley (Shin et al. 2008), as well as a polygalacturonase-inhibiting protein (Ferrari et al. 2012) all directly inhibit pathogen growth, whereas pectin methyl-esterase inhibitor-mediated resistance (Ferrari et al. 2012 ) is associated with the inability of $F$. graminearum to grow on methyl-esterified pectin. Zealexin, a sesquiterpenoid phytoalexin, has been identified in maize to inhibit $F$. $g r a-$ minearum growth, because an increased level of zealexin could reduce cob rot in maize (Huffaker et al. 2011). A UDPglucosyltransferase from Arabidopsis was involved in DON detoxification by converting DON to nontoxic DON-3-glucoside (Poppenberger et al. 2003). Sulphamethoxazole and the indole alkaloid gramine also provide protection against $F$. graminearum in wheat (Schreiber et al. 2011).

A number of quantitative trait loci (QTL) mapping studies have been conducted for wheat and barley. In wheat, a single QTL on chromosome 3BS, Fhb1, explains 20 to $60 \%$ of the total variation for FHB resistance (Pumphrey et al. 2007). Wheat Fhbl reduces the toxicity of the mycotoxin DON by converting DON to DON-3-glucoside (Lemmens et al. 2005), thereby lessening the symptoms resulting from $F$. graminearum infection. A pair of near-isogenic lines (NIL) of wheat, which carry either the resistant or susceptible Fhbl allele, has been used to perform a genome-wide assessment of the F. graminearum -infection response. A large number of genes were shown to respond to $F$. graminearum infection (Golkari et al. 2009; Jia et al. 2009, 2011). To date, studies in both wheat and barley indicate that host genes induced during $F$. graminearum infection are similar to those induced by many other plantmicrobe interactions (Bischof et al. 2011).

We identified the QTL $q R f g 1$ on chromosome 10 that could explain $36.6 \%$ of the total variations of maize resistance to stalk rot (Yang et al. 2010). The QTL $q R f g l$ was later finemapped to a single gene encoding a transcription regulator (unpublished data). Here, we used two maize NIL, which carry either the resistant $q R f g l$ allele (R-NIL) or the susceptible $q R f g 1$ allele (S-NIL), to evaluate $q R f g l$ function in resistance to $F$. graminearum infection. After inoculating these plants with $F$. graminearum, we analyzed disease symptoms, pathological alterations to both cellular and subcellular structures, and changes to the root transcriptome.

\section{RESULTS}

Disease severity varies in primary roots of the two NIL.

Primary roots (i.e., approximately 6 to $8 \mathrm{~cm}$ in length without lateral roots) (Fig. 1A) from both R-NIL and S-NIL were inoculated with $F$. graminearum macroconidia and incubated at $26^{\circ} \mathrm{C}$. At $48 \mathrm{~h}$ after inoculation (hai), dark-brown lesions were apparent on both the primary root and some early lateral roots. Typically, the middle part of the root shrunk and turned dark brown, whereas the upper and lower portions, which flanked the diseased region, retained a normal appearance (Fig. 1D). The two NIL differed in both disease incidence and the speed of lesion progression. For R-NIL, light-brown lesions were observed on the infected part of the root until 36 hai. By 48 hai, however, approximately $80 \%$ of the R-NIL roots displayed a generally healthy phenotype, with mild, light-brown lesions that were not shrunken (a resistant phenotype) (Fig. 1B and $\mathrm{C}$ ). In contrast, the early brown lesions were visible in infected S-NIL roots at 18 hai. These lesions expanded over time, reaching approximately $2 \mathrm{~cm}$ in length at 36 to 48 hai. By 48 hai, approximately $60 \%$ of the S-NIL roots displayed 
severe necrotic lesions (approximately $2 \mathrm{~cm}$ in length, which were dark brown and shrunken in appearance; a susceptible phenotype) (Fig. 1D). The percentage of diseased primary roots with necrotic lesions was $20.3 \pm 5.0$ and $50.9 \pm 8.8 \%$ for R-NIL and S-NIL, respectively $(P \leq 0.001)$.

Because disease symptoms always appeared in the middle part of the root 48 hai, we investigated the connection between $F$. graminearum inoculation and disease presentation. We marked the root tips at the time of inoculation and observed root growth for $48 \mathrm{~h}$. This analysis showed that the diseased part of the root was the root tip at the time of inoculation. As such, the principal $F$. graminearum entry site was located in the root tip or meristem. The infected root tip became diseased but the upper root segment (root tissue that was above the root tip at the time of inoculation) and root tissue that was grown after inoculation did not (Fig. 1D). To confirm this observation, we inoculated only the root tips (approximately $0.5 \mathrm{~cm}$ of root tissue) with $F$. graminearum and incubated the plants for $48 \mathrm{~h}$. Results were identical to the whole-root inoculations. This implies that $F$. graminearum infects maize root in a tissuespecific manner (the tip or meristem), causing disease symptoms only within the initially infected tip region.

\section{Pathological changes to root tissue \\ following $F$. graminearum infection.}

To observe pathological changes underlying the root lesions, free-hand transverse sections were prepared from both R-NIL and S-NIL diseased root fragments. For R-NIL lesions, epidermal cells showed no sign of shrinkage, and only some of these cells turned brown. Intriguingly, a number of dark dots were scattered within the cortical cells (Fig. 2A). In the diseased SNIL roots, however, nearly all the epidermal and most of the cortical cells collapsed and turned brown (Fig. 2B). To visualize these pathological changes in detail, diseased root segments were embedded in paraffin and transverse sections were prepared. For R-NIL roots, cavities were observed among cortical cells, whereas cell shrinkage was apparent in S-NIL roots (data not shown). To ensure that these pathological changes (e.g., cavities and cell shrinkage) did not result from the sectioning process, semi-thin $(3 \mu \mathrm{m})$ transverse sections were prepared from the same diseased root segments. Clear and definite cavities and an intact epidermal cell layer were again observed in the R-NIL roots (Fig. 2C and E). These cavities seemed to result from severe structural damage to cortical cells. In S-NIL roots, however, all the epidermal cells and most of the cortical cells exhibited severe shrinkage (Fig. 2D and F). These findings suggested that different mechanisms may underlie cell death in the R-NIL and S-NIL roots.

\section{The fungal infection structure and biomass in the roots.}

To determine how $F$. graminearum hyphae invade the maize root, entry regions (i.e., the root tips at the time of inoculation) were collected at $12,24,36$, and 48 hai and subjected to scanning electron microscopy. On the S-NIL root surface, numerous enlarged primary hyphae with irregular shapes (also called short-infection hyphae) emerged from septa of the macroconidia at 12 and 24 hai and directly penetrated cells of the epidermis. No specialized penetration structures, such as appressoria, formed on the maize root during infection but, rather, only a simple peg-like structure at the infection site (Supplementary Fig. S1A to C). As the F. graminearum invasion progressed, large numbers of slender and regularly shaped secondary hyphae appeared on the root surface (36 hai). By 48 hai, some hyphae had sporulated (a round morphology). Primary hyphae typically indicate biotrophic growth, whereas secondary hyphae indicate necrotrophic growth (Zhang et al. 2012). Therefore, on the maize root, $F$. graminearum gradually switches from biotrophic to necrotrophic growth because the secondary hyphae became visible on the roots 12 and 24 hai, and covered the whole root 36 hai.

To assess the connection between fungal biomass and disease severity, we compared samples from the diseased root segment and the adjacent upper segment (approximately $2 \mathrm{~cm}$ in length). Large amounts of fungal growth were visible on the surface of R-NIL roots with mild lesions (Fig. 3A) but many more hyphae were packed on the S-NIL root surfaces that contained severe lesions (Fig. 3B). The $\log _{10}$ clone-forming units per gram fresh weight of roots was estimated to be $6.97 \pm 0.21$ and $7.96 \pm 0.25$ for the diseased root segments of R-NIL (Fig. 3A) and S-NIL (Fig. 3B), respectively. This indicates that the amount of hyphae was 10 times more on diseased segments of the S-NIL roots than that of the R-NIL roots (Fig. 3E). In contrast, the upper segments of R-NIL (Fig. 3C) and S-NIL (Fig. 3D) contained similar amounts of $F$. graminearum hyphae, approximately $1 / 10$ of the amounts of the diseased S-NIL segments (Fig. 3E). These suggest that fungal biomass correlates with disease severity and that the unfettered growth of $F$. graminearum hyphae within the S-NIL root causes severe disease symptoms.

\section{Hyphal spread and colonization within the root.}

To investigate the spread and colonization of $F$. graminearum hyphae in maize roots, we constructed a transgenic strain of $F$. graminearum that stably expressed a gene encoding en-

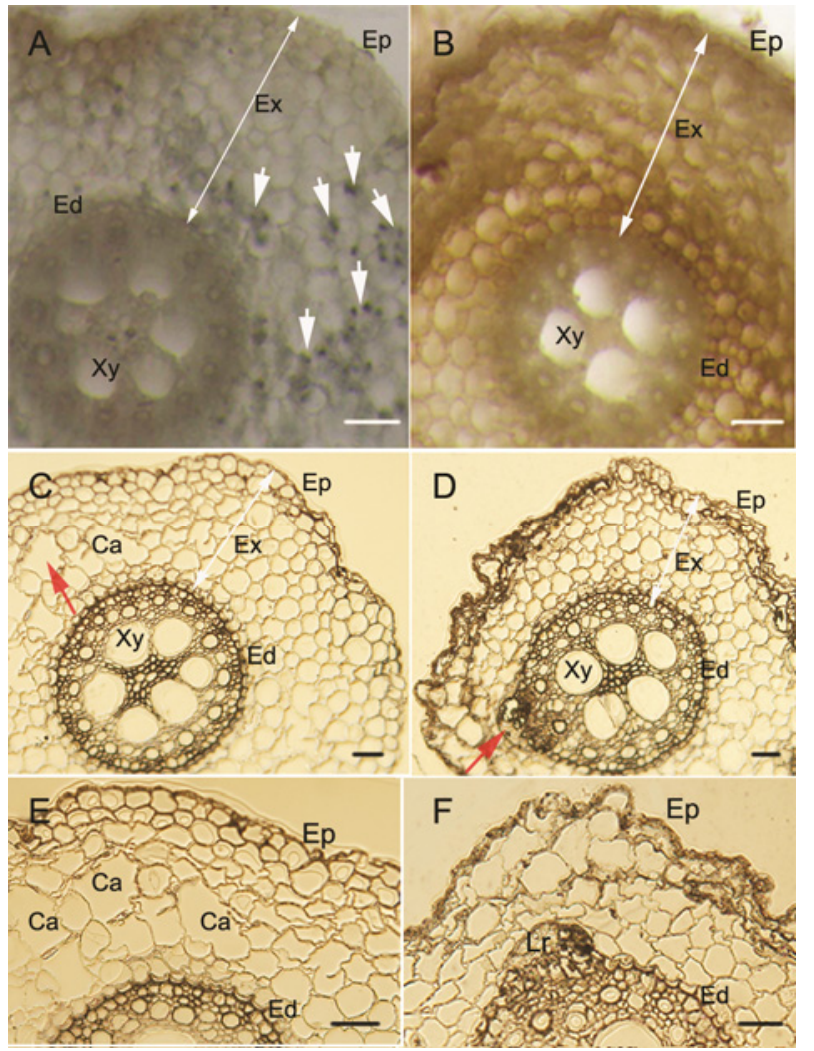

Fig. 2. Resistant and susceptible near-isogenic line (R-NIL and S-NIL, respectively) roots exhibit different pathological changes to exodermal tissues following Fusarium graminearum infection. A, At $48 \mathrm{~h}$ after inoculation (hai), exodermal cells within the light-brown lesions of R-NIL roots had scattered dark spots (white arrows). B, Exodermal cells within S-NIL lesions (48 hai) were dark brown and severely shrunken. Semithin transverse sections revealed $\mathbf{C}$, cavity formation among cortical cells within lesions of RNIL roots and D, severe cell shrinkage and deformation of exodermal cells within lesions of S-NIL roots. $\mathbf{E}$ and $\mathbf{F}$, Magnified views of regions indicated by red arrows in $\mathrm{C}$ and $\mathrm{D}$, respectively. Double-sided arrows indicate the exodermis. Ca, cortical-cell cavity; Ed, endodermis; Ep, epidermis; Ex, exodermis; Lr, lateral-root initiation; Xy, xylem. Scale bars $=100 \mu \mathrm{m}$. 
hanced cyan fluorescent protein (CFP) but maintained strong pathogenicity. Maize roots were inoculated with this strain, and free-hand transverse sections were prepared from segments of the diseased root. Hyphal spread or colonization was monitored by detecting the CFP signal via laser-scanning confocal microscopy. In R-NIL roots, the majority of hyphae colonized the exodermis (i.e., the epidermis and several layers of cortical cells); only a few hyphae reached the vascular cylinder (Fig. 4A). In upper, nondiseased segments of R-NIL roots, we observed thickened cell walls and the formation of papillae with growing hyphae inside (data not shown). However, for diseased
S-NIL roots, large amounts of hyphae spread from the darkbrown root surface, colonized the exodermis, and accumulated inside the vascular cylinder (Fig. 4B). The CFP signal indicated that most $F$. graminearum hyphae preferentially grew within intercellular spaces of the maize-root tissue, while some were found inside host cells (Fig. 4C and D). Compared with R-NIL roots, many more hyphae colonized the S-NIL root tissue, consistent with results from both scanning electron microscopy and biomass analyses (Fig. 3E). This further supported the hypothesis that high levels of hyphal colonization results in severe disease symptoms within S-NIL roots.
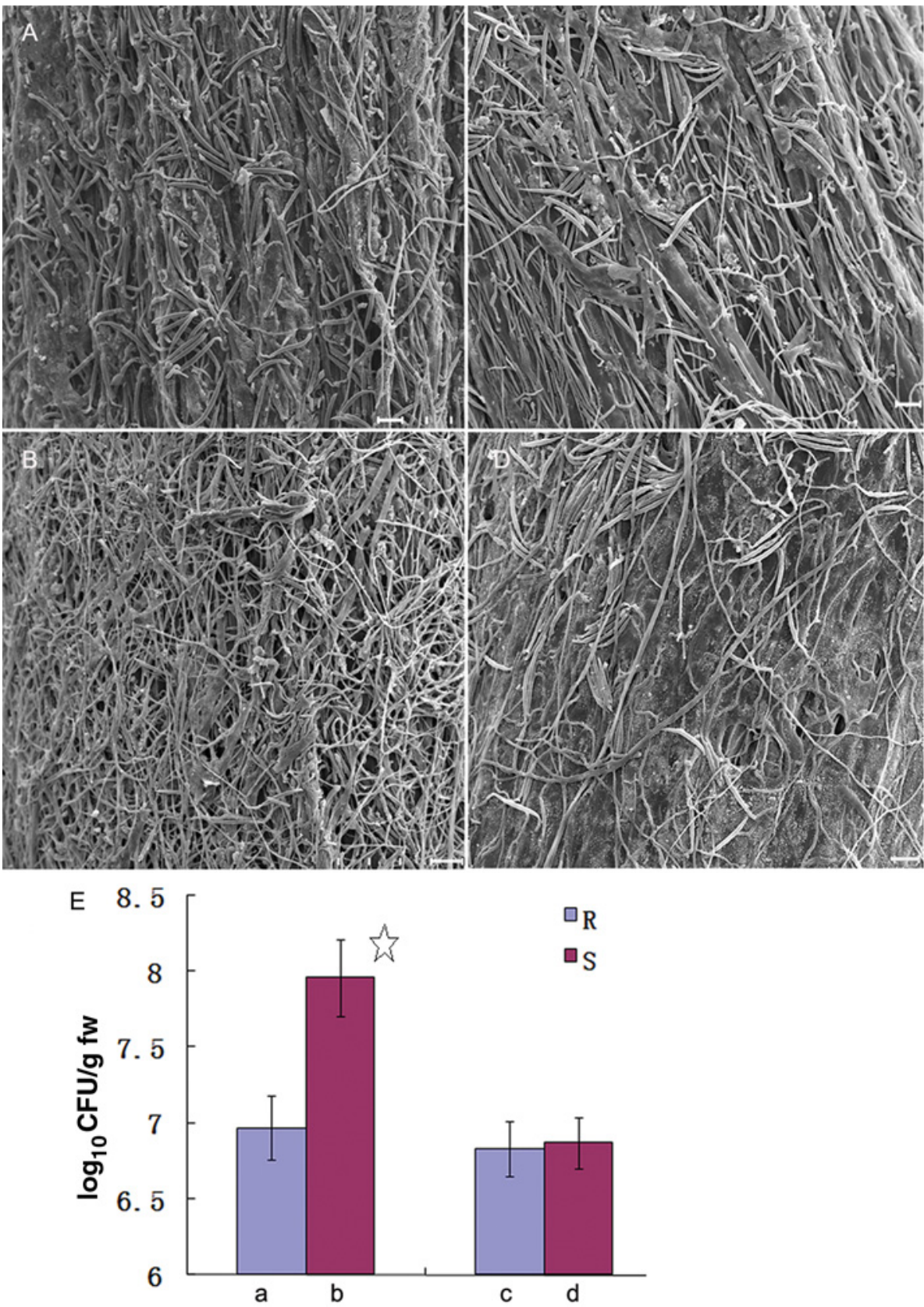

Fig. 3. Hyphae micrographs and quantitative analysis of the fungal biomass in Fusarium graminearum-inoculated maize roots. Following inoculation of resistant near-isogenic line (R-NIL) roots, plentiful hyphae were found A, on the surface of light diseased lesions (approximately $2 \mathrm{~cm}$ in length), as well as C, root segments immediately adjacent to the lesions $(2 \mathrm{~cm}$ above the disease sight). For susceptible (S)-NIL roots, B, fungal hyphae densely packed on the surface of diseased regions (approximately $2 \mathrm{~cm}$ in length) but $\mathbf{D}$, fewer hyphae grew on the adjacent regions $(2 \mathrm{~cm}$ above the disease site). $\mathbf{E}$, Quantitative analysis of the fungal biomass associated with diseased and nondiseased regions of R-NIL and S-NIL roots ( $\mathrm{R}=\mathrm{R}-\mathrm{NIL}$ and $\mathrm{S}=\mathrm{S}-\mathrm{NIL})$. Letters a through d in the $x$ axis correspond to the different root samples shown in A through $\mathrm{D}$, respectively. The $y$ axis represents the fungal biomass estimated with $\log _{10}$ clone-forming units per gram fresh root weight $\left(\log _{10} \mathrm{CFU} / \mathrm{g} \mathrm{fw}\right)$. Data represent the mean of three independent replicates with standard deviation (SD). An asterisk indicates a significant difference between the R-NIL ("a" for that shown in A visually) and the S-NIL ("b" for that shown in B visually) diseased root segment $(P<0.05, t$ test $)$. Scale bars $=20 \mu \mathrm{m}$ in A, B, and D and $30 \mu \mathrm{m}$ in C. 


\section{F. graminearum infection}

\section{disrupts subcellular organelles in maize root.}

Although no symptoms were observed in upper-root segments immediately adjacent to the diseased root segments, large amounts of $F$. graminearum hyphae grew on the surface of these upper regions (Fig. 3). Transverse ultrathin sections were prepared from the upper-root regions, and subcellular changes were investigated via transmission electronic microscopy. For R-NIL roots, most parenchyma cells of the cortex were characterized by plasmolysis, mitochondrial linearization, and swollen mitochondria that had distorted cristae (Fig. 5A and B). However, within S-NIL roots, parenchyma cells of the cortex exhibited severe cellular degradation with a discontinuous plasma membrane, swollen mitochondria with distorted cristae, vacuolated mitochondria, and degraded nuclei (Fig. 5E and F).

Within the exodermis of both R-NIL and S-NIL diseased root fragments, the subcellular morphology of these $F$. graminearum hyphae were examined. In particular, individual thin $F$. graminearum hyphae were observed scattered in the intercellular space of the cortex parenchyma cells of R-NIL roots (Fig. 5C and D), whereas multiple thick membrane-coated $F$. graminearum hyphae were observed in the intercellular space of S-NIL roots (Fig. 5G and H). We used transverse ultrathin sections of exodermis from upper-root segments, which lacked visible symptoms, to observe cell-wall thickening. Although exodermal cells of both R-NIL and S-NIL roots exhibited severe cellular degradation, differences in cell-wall structure were apparent. In R-NIL roots, cell-wall thickening (dark, electron-dense depositions) was apparent between cells at the corners of intercellular spaces (Supplementary Fig. S2A and B). This contrasted with the uniformly thin cell wall that characterized the dead and dying cells of the S-NIL root. These findings suggested that $F$. graminearum hyphae flourish in $\mathrm{S}$ NIL root tissue, where they are protected by a membrane coating. F. graminearum growth, however, is inhibited within R-NIL roots because of an insufficient membrane coating and reinforced cell walls within host tissues.

\section{Molecular basis underlying maize resistance to $F$. graminearum infection.}

To comprehensively investigate the molecular basis of maize resistance to $F$. graminearum infection, we sequenced the transcriptome of maize-root samples. First, mRNA was isolated from R-NIL and S-NIL roots that were collected at $0,6,18$, and 48 hai. The mRNA was then sheared and used to construct a cDNA library for mRNA-seq. Approximately 87.3 and 103.2 million high-quality reads were generated from R-NIL and SNIL transcriptomes, respectively. Analysis of read distribution for the four R-NIL transcriptomes (R0, R6, R18, and R48) showed that most reads $(66.1 \%)$ mapped to protein-coding genes. The remaining reads were distributed among introns (4.6\%), repetitive regions $(0.5 \%)$, intergenic regions $(11.4 \%)$, and splice junctions (17.4\%). A similar read distribution was obtained for the four S-NIL transcriptomes. These results showed that high-throughput sequencing could be used to survey gene expression profiles in the maize root.

Changes in gene expression that resulted from inoculation $(6,18$, and 48 hai) were calculated relative to the control (0 hai). Genes were considered differentially expressed if a twofold change in expression was detected $\left(P<1 \times 10^{-3}\right.$, false discovery rate $\left.[\mathrm{FDR}]<1 \times 10^{-3}\right)$. Analysis of shared and unique differentially expressed genes (DEG) from the time course of R-NIL (Fig. 6A) and S-NIL (Fig. 6B) transcriptomes revealed that most DEG $(>60 \%)$ were either consistently upregulated or downregulated throughout the infection process (6 to 48 hai). The number of DEG peaked at 18 hai $(2,507)$ for the R-NIL and at 48 hai $(1,919)$ for the S-NIL. Moreover, there were more upregulated DEG in the R18 and R48 transcriptomes (Fig. 6C), whereas downregulated DEG were more plentiful in all transcriptomes of the S-NIL time course (Fig. 6D).

A large number of genes involved in diverse biological pathways were dramatically upregulated or downregulated during infection. We performed a Kyoto Encyclopedia of Genes and Genomes (KEGG) pathway analysis and determined that, for DEG from R18, 1,698 were components of 111 KEGG pathways. Of these pathways, 17 had $Q$ values $<0.05$, and pathways with the lowest $Q$ values included biosynthesis of four alkaloids, biosynthesis of phenylpropanoids, biosynthesis of plant hormones, biosynthesis of terpenoids and steroids, the citrate cycle,
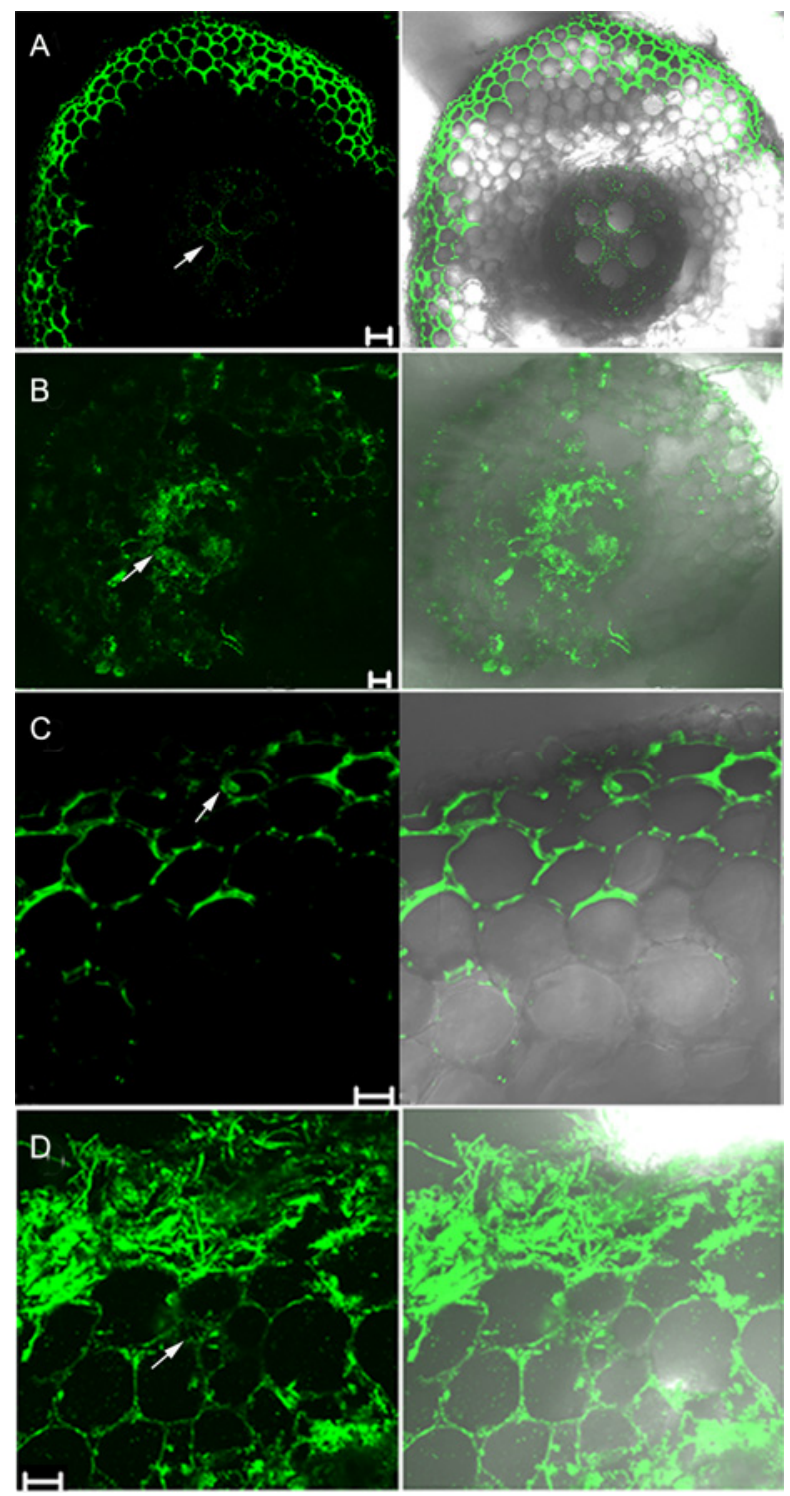

Fig. 4. Growth and distribution of fungal hyphae in diseased root tissues of resistant and susceptible near-isogenic line (R-NIL and S-NIL, respectively) plants. A, For R-NIL root $48 \mathrm{~h}$ after inoculation (hai), Fusarium graminearum hyphae grew within intercellular spaces of a few outer layers of exodermal cells. B, Hyphae colonized the entire S-NIL root 48 hai, including epidermal cells, cortical cells, and the vascular cylinder. Arrows in $\mathrm{A}$ and $\mathrm{B}$ indicate fungal colonization in the vascular cylinder. Some host cells from both $\mathbf{C}$, R-NIL and D, S-NIL D plants were colonized by fungal hyphae. Arrows in $\mathrm{C}$ and $\mathrm{D}$ indicate fungal colonization within the host cells. Images to the left are dark field with cyan fluorescent protein filters for 470-nm excitation. Images to the right are overlays of dark-field and bright-field images. Transverse sections of diseased root segments were cut by free-hand. All images were obtained via confocal microscopy. Scale bars $=50 \mu \mathrm{m}$ in $\mathrm{A}$ and $\mathrm{B}$ and $20 \mu \mathrm{m}$ in $\mathrm{C}$ and $\mathrm{D}$. 
pyruvate metabolism, and the ribosome pathways (Fig. 6E). For S18, 1,202 DEG matched 86 KEGG pathways, of which 23 had $\mathrm{Q}$ values $<0.05$. Lowest $\mathrm{Q}$ values were associated with oxidative phosphorylation, pyruvate metabolism, metabolic pathways, glycolysis and gluconeogenesis, and biosynthesis of plant hormones (Fig. 6F). Pathway-enrichment clustering analysis was performed using DEG from each of the time-course transcriptomes (Supplementary Table S1). For each KEGG pathway, we calculated the percentage of genes involved in that pathway that were also DEG. In each case, these values were higher in R-NIL samples than in S-NIL samples, which led to enrichment-test $P$ values that were lower in R-NIL transcriptomes compared with S-NIL transcriptomes. Concerning both percentages and enrichment, however, differences between the R-NIL and S-NIL transcriptomes were smallest at 48 hai. These data indicated that the defense response was more rapid and intense in R-NIL than in S-NIL. DEG involved in the biosynthesis pathways for alkaloids, phenylpropanoids, and plant hormones were significantly enriched in the R6, R18, and R48 transcriptomes. Some of these biosynthesis pathways were also enriched in S-NIL transcriptomes but these enrichments were delayed and of lesser magnitude. This suggests that secondary metabolic pathways (e.g., biosynthesis of alkaloids and phenylpropanoids) and plant hormones may play important roles in maize resistance to $F$. graminearum-induced stalk rot.

$F$. graminearum infection elicited a complex transcription response in maize-root tissue. First, the regulation (up or down) of 38 transcription factors (TF) became more pronounced as infection progressed. These TF included two $\mathrm{CCCH}$, three NAC, four ET-responsive TF, 10 MYB, seven WRKY, and 12 others. Fold changes associated with these TF were much larger in R-NIL samples than in S-NIL samples (Supplementary Table S2). Similarly, 21 genes encoding elongation factors were dramatically up- or downregulated during $F$. graminearum infection (data not shown). Second, F. graminearum infection dramatically upregulated the expression of defense-related genes in RNIL transcriptomes but not so much in S-NIL transcriptomes. These defense genes encode six PRs, two chitinases, nine perox- idases, two glucanases, four heat-shock proteins, two mitochondrial chaperonins, and three $\beta$-expansins, for example. Finally, expression levels of many stress-responsive genes (e.g., 12 peroxidases, 17 glutathione S-transferases, $12 \mathrm{NADH}$ dehydrogenases, 19 histones, and 22 other genes involved in methylation) were dramatically up- or downregulated at each time point of $F$. graminearum infection. Intriguingly, the two NIL displayed basal expression difference of DEG in noninoculated roots, and levels of expression for all the upregulated DEG were lower in the R-NIL control (R0) than in the S-NIL control (S0), whereas the expression level of all the downregulated DEG was higher in R0 than in S0. These data suggested a comprehensive defense response that contributes to stalk-rot resistance in maize.

To confirm that $F$. graminearum infection upregulates defense-related genes in R-NIL roots more so than in S-NIL roots, 16 defense-related genes identified using RNA-seq were subjected to real-time reverse-transcriptase quantitative polymerase chain reaction (RT-qPCR). For eight of these genes, relative expression levels were entirely consistent between the RT-qPCR and RNA-seq techniques (Supplementary Tables S3 and S4), although there was variability in the absolute expression fold-change values.

\section{The role of lignin and phenolic acids in maize resistance to $F$. graminearum infection.}

The deposition of lignin, a component of the host defense system, was investigated in both R-NIL and S-NIL maize roots via histochemistry. For R-NIL roots, lignin was deposited in the epidermal cell layer and the outer two or three layers of cortical cells and the vascular cylinder (Fig. 7A). In contrast, no lignin was deposited among epidermal or cortical cells of S-NIL roots, whereas a lot of lignin was deposited in the vascular cylinder (Fig. 7B). We also used high-performance liquid chromatography (HPLC) to measure the concentration of SA and three phenolic acids that are involved in lignin biosynthesis. Phenols have been shown to slow (or even halt) growth of the pathogen (Beckman 2000; Dixon 2001; Nicholson and Hammerschmidt 1992). Before F. graminearum inoculation, the
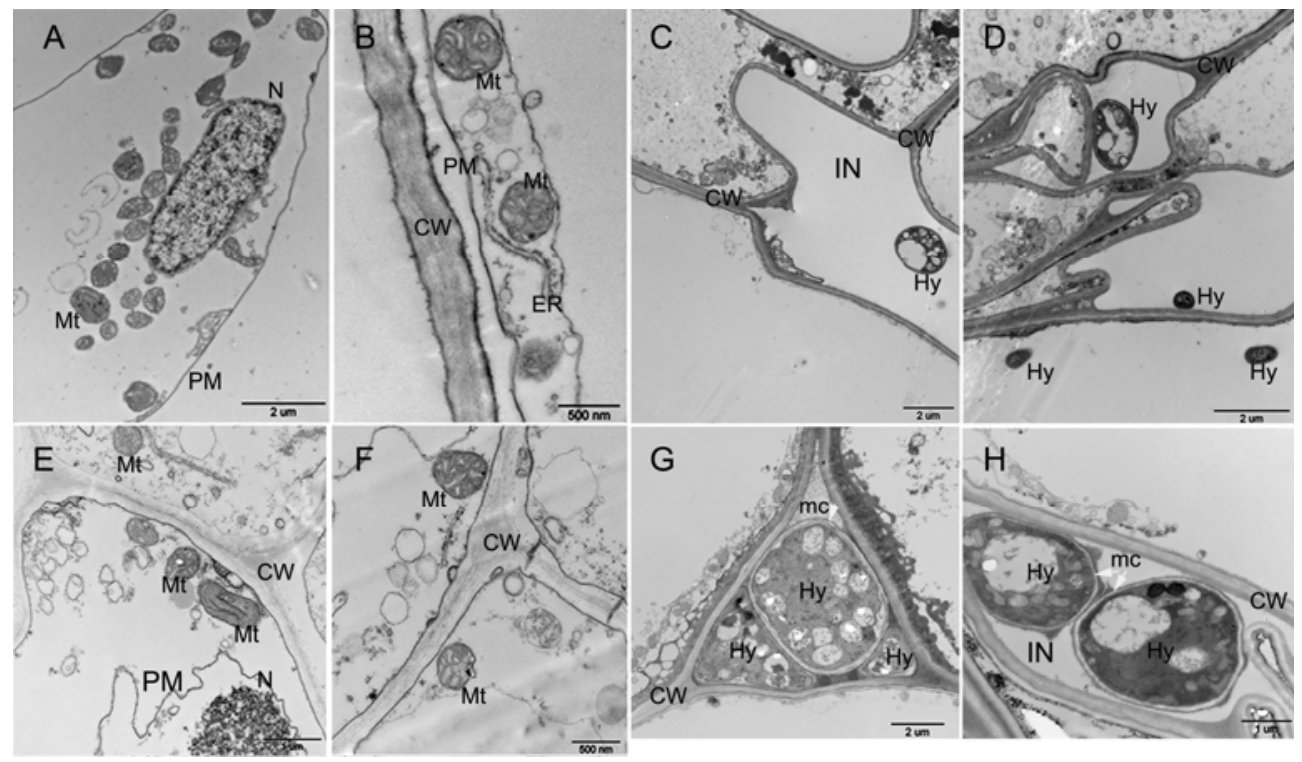

Fig. 5. Subcellular changes associated with root cortical cells and hyphal growth among exodermal cells. A and B, Plasmolysis and swollen mitochondrial cristae were observed in resistant near-isogenic line (R-NIL) cortical cells $48 \mathrm{~h}$ after inoculation (hai). C and D, Single Fusarium graminearum hyphae that lacked membrane coating were observed among cortical cells of R-NIL root 48 hai. E and F, Parenchyma cells of the susceptible (S)-NIL root cortex cells 48 hai were characterized by plasma membrane (PM) disruptions, vacuole membrane disruptions, and disordered organelles (e.g., nuclear degradation and the swelling of mitochondrial cristae). G and H, S-NIL root 48 hai also contained thick $F$. graminearum hyphae with membrane coatings that grew within intercellular spaces of dead cortical cells. CW, cell wall; Hy, fungal hyphae; ER, endoplasmic reticulum; IN, intercellular space; Mt, mitochondrion; N, nucleus; mc, hyphal membrane coating. Scale bars are shown in each image. 
concentrations of SA and the three phenolic acids were much higher in R-NIL roots than in S-NIL roots (Fig. 7C), suggesting that R-NIL roots store more preformed phenolic acids. Once the roots were inoculated, the concentrations of SA and the three phenolic acids decreased in R-NIL roots, whereas levels of SA and the three phenolic acids did not change much in S-NIL roots (Fig. 7C). The sharp decrease in phenolic acid levels within R-NIL roots suggested that these phenols may serve as a reservoir that is converted to other products (e.g., phytotoxin) after pathogen infection.

\section{DISCUSSION}

\section{QTL $q R f g 1$ restricts fungal spread but} does not block infection.

Successful infection by a plant pathogen results in the death of host cells and the onset of disease symptoms. Conversely, successful pathogen resistance by the host is often associated with a hypersensitive response, which restricts the pathogen to a local population of dead cells, followed by systemic acquired resistance to the pathogen. The hypersensitive response allowing the plant to control its own cellular destiny, triggered by an intrinsic PCD (Pennell and Lamb 1997; Richberg et al. 1998). Genes encoding PCD-related proteins are reported to be induced during the interaction between wheat and $F$. graminearum (Jia et al. 2009). In R-NIL roots, the formation of cavities among the cortical cells may result from PCD (Fig. 2).

During $F$. graminearum infection, foot structures and compound appressoria form on the inoculated wheat floret (Boenisch and Schäfer 2011). In this study, numerous primary hyphae grew and spread on the maize-root surface as early as 12 hai. Many primary hyphae directly penetrated the epidermal cells but no specialized penetration structure was found. The absence of a penetration structure could have resulted from the lack of cuticle wax on the maize-root surface. No disease symptoms (e.g., cellular shrinkage or changes in color)
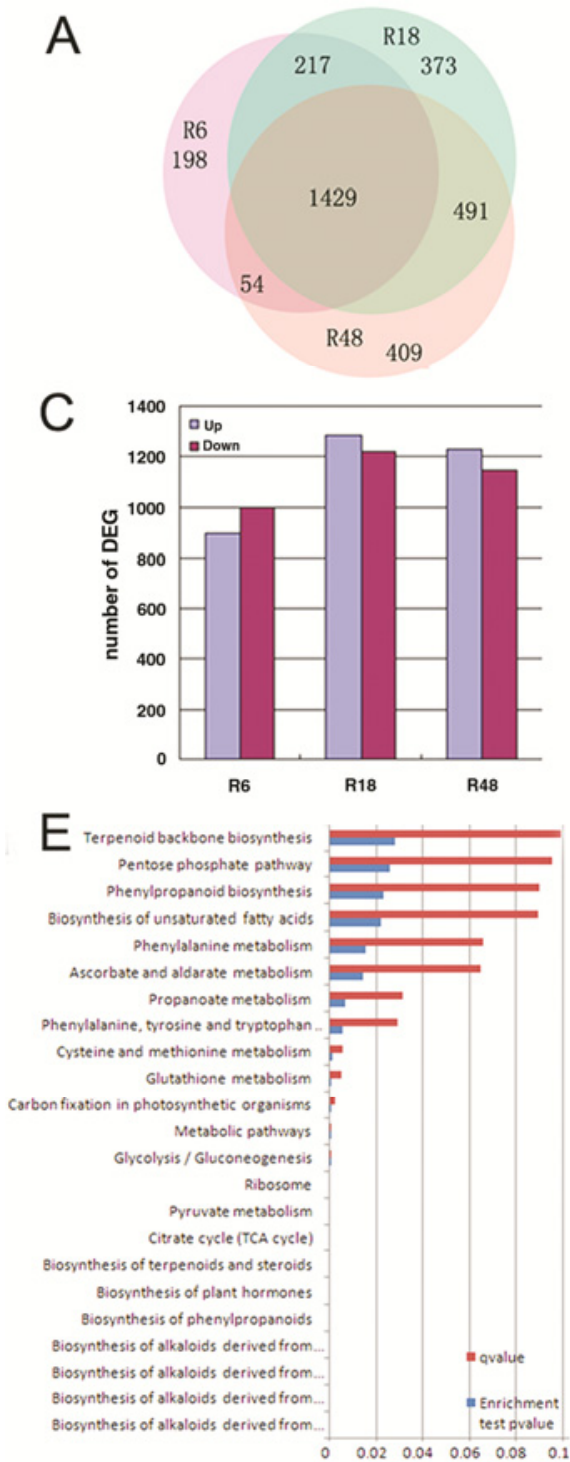

B

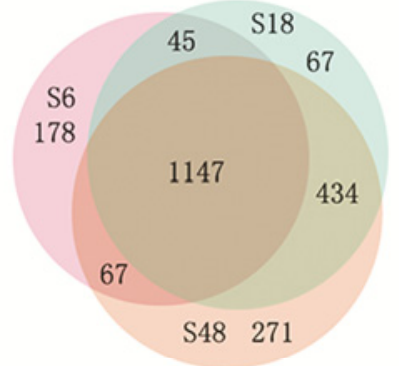

D
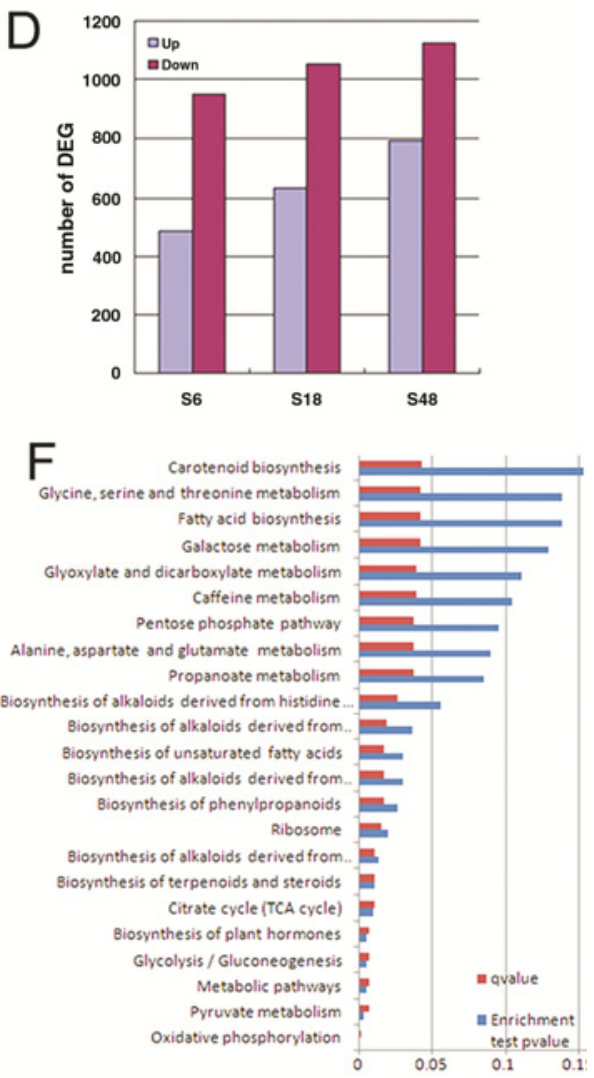

Fig. 6. Characterizing the maize-root transcriptome during Fusarium graminearum infection reveals the molecular basis of resistance. Transcriptome analysis revealed both shared and unique differentially expressed genes (DEG) during a time-course of $F$. graminearum infection for A, resistant near-isogenic line (R-NIL) and B, susceptible (S)-NIL roots. DEG were identified by comparing expression levels from root samples taken at 6,18 , or $48 \mathrm{~h}$ after inoculation (hai) to time-zero controls. R6, R18, and R48 were compared with R0 whereas S6, S18, and S48 were compared with S0. C, More DEG were upregulated at R18 and R48 whereas D, more DEG were downregulated throughout the S-NIL time course; up = upregulated and down = downregulated. $\mathbf{E}$ and $\mathbf{F}$, Kyoto Encyclopedia of Genes and Genomes pathway clustering analysis using DEG from E, the R18 versus R0 comparison or F, the S18 versus S0 comparison. Biosynthetic pathways for phenylpropanoids, plant hormones, and four alkaloids were significantly enriched at R18 (E). Pathways involved in oxidative phosphorylation and pyruvate metabolism were significantly enriched at S18 (F). 
were observed at this time. As a hemibiotrophic pathogen, $F$. graminearum does not kill its host cells during the early biotrophic growth phase in maize roots. However, the later phase of necrotrophic growth (48 hai) was characterized by extensive cell death, tissue necrosis, and a massive accumulation of fungal biomass (Figs. 1 and 3).

F. graminearum hyphae enter plant tissue via wounds or natural openings or by directly penetrating the plant surface. Here, $F$. graminearum infected the maize root primarily through the root tip (cells of the root meristem that lack a fortified cell wall), causing disease symptoms within the infected region of the root by 48 hai, consistent with the well-known phenomenon that many soilborne pathogens infect the roots through auxin-rich regions, such as root tips and lateral root initials. In R-NIL roots, hyphal growth was confined to several layers of exodermal cells (Fig. 4A), whereas hyphal propagation in S-NIL roots was robust and unconstrained (Fig. 4B). The entire S-NIL root (i.e., the whole exodermis and the vascular cylinder) was colonized by huge numbers of hyphae (Fig. 4B). This caused rapid necrosis, shrinkage, and browning of root cells. Colonization of the vascular cylinder would likely destroy the conducting tissue of the host, resulting in severe disease symptoms. The majority of hyphae were found within intercellular spaces of both R-NIL and S-NIL roots (Fig. 4C and D). When hyphae were found within host cells, these cells were generally dead (Fig. 5). In wheat and barley, F. graminearum infection causes the degradation of chloroplasts (Kang and Buchenauer 2000). Here, we observed plasmolysis and mitochondria degradation in infected R-NIL roots (Fig. 5A and B). More severe cellulardegradation phenotypes (e.g., disruption of the plasma mem-
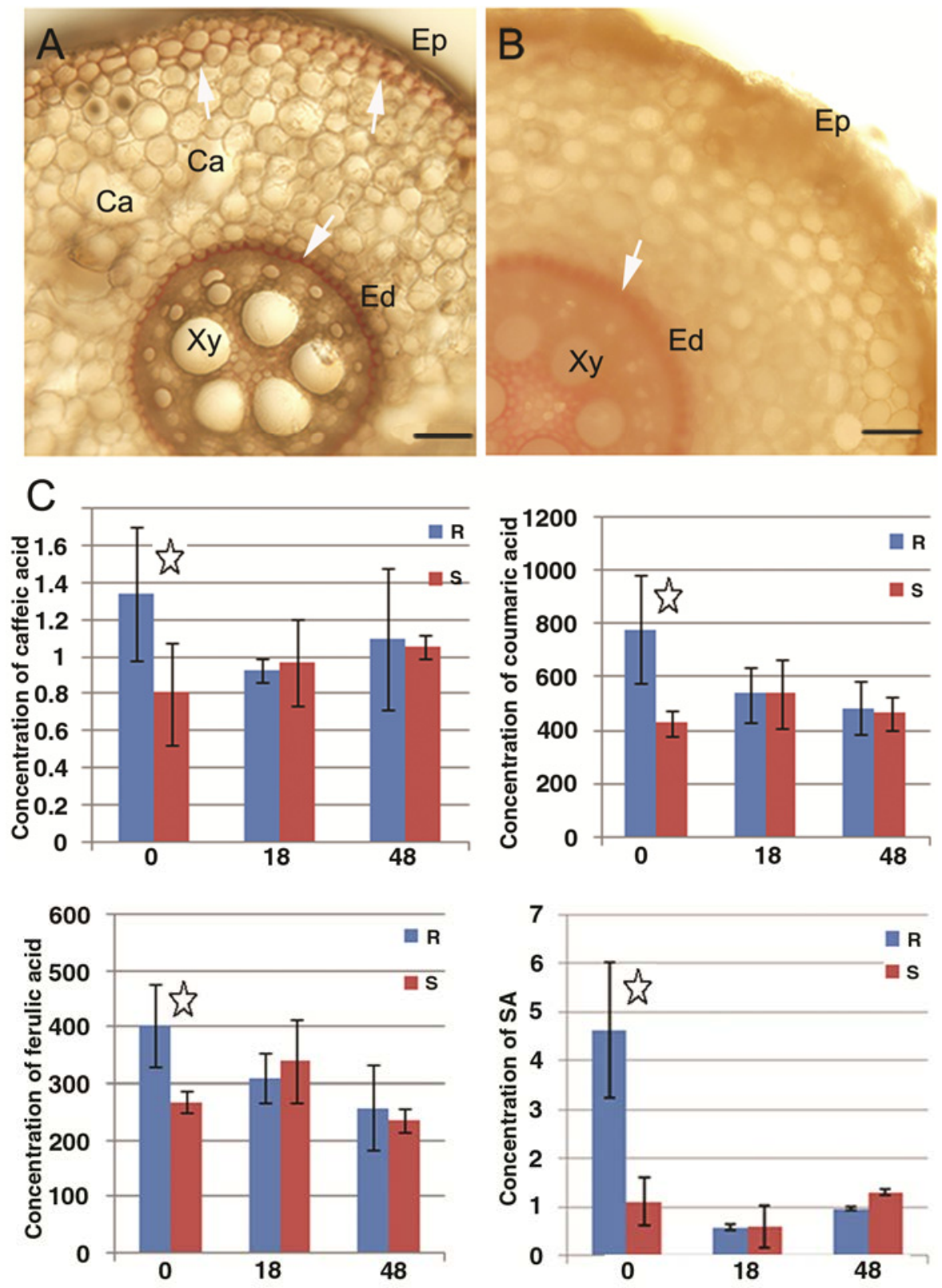

Fig. 7. Distribution of lignin and phenolic acid concentrations in maize roots. The distribution of lignin in transverse sections of $\mathbf{A}$, resistant near-isogenic line (R-NIL) and B, susceptible (S)-NIL maize root tissues was determined using the histochemical reagent phloroglucinol-HCI. Arrows indicate lignin deposition (in red color). C, Concentrations of phenolic acids in R-NIL and S-NIL maize-root tissues were measured by high-performance liquid chromatography. Data represent the mean of three independent replicates with standard deviation (SD). An asterisk indicates a significant difference between the R-NIL and the S-NIL at $0 \mathrm{~h}$ after inoculation (hai) $(P<0.05, t$ test). The $y$ axis represents the concentration of phenolic acid ( $\mu$ g/g fresh root weight). The $x$ axis indicates the time after inoculation. Ca, cavity among cortical cells; Ed, endodermis; Ep, epidermis; Xy, xylem; R, R-NIL; S, S-NIL. Scale bars are $100 \mu$ m. 
brane, mitochondria, and the nucleus) were observed in S-NIL roots (Fig. 5E and F). Moreover, dystrophic growth of hyphae that lacked a membrane coating was observed in R-NIL roots (Fig. 5C and D). In contrast, S-NIL roots contained membranecoated $F$. graminearum hyphae (Fig. $5 \mathrm{G}$ and $\mathrm{H}$ ). These data suggest that QTL $q R f g 1$ restricts $F$. graminearum growth and spread within maize roots during infection but does not block the initial infection.

\section{Phenolic acids may contribute \\ to $F$. graminearum resistance in maize.}

Low molecular weight phenols, especially the phenylpropanoids (e.g., coumaric and ferulic acids), are involved in initial responses to stress. This results in the accumulation of phytoalexins as well as the esterification of ferulic acid to cell walls (Beckman 2000; Nicholson and Hammerschmidt 1992). Specialized phenolic-storing cells are scattered throughout cortical, pith, and xylem parenchyma tissues of cotton root (Beckman 2000). Phenols rapidly accumulate at the site of infection, which is speculated to slow or halt pathogen growth. Furthermore, phenols can activate certain pathways to further restrict pathogen growth. In maize, this lesion restriction elicits the formation of a "stress lignin" (Beckman 2000).

In this study, S-NIL roots turned brown by 18 hai and dark brown by 48 hai, whereas R-NIL roots remained light brown until 48 hai (Fig. 1). High levels of caffeic acid, cinnamic acid, and ferulic acid (involved in lignin biosynthesis) were measured in R-NIL control roots (R0) compared with S-NIL controls (Fig. 7C). This indicates that R-NIL roots stored more phenolic acids than S-NIL roots. Similarly, genotypes of wheat that are resistant to $F$. graminearum have higher levels of cinnamic acid and ferulic acid than susceptible genotypes (Hamzehzarghani et al. 2005, 2008). It is assumed that the initial defense response is very rapid, with no time for de novo biosynthesis of these toxic phenols. During the defense response, phenols are esterified to cell walls, and their covalent attachment to cell walls beyond the infection site may precede the onset of visible necrosis at the infection site (Beckman 2000). High levels of preformed phenols in R-NIL roots (Fig. 7C) would enable an emergency immune response, which would inhibit hyphal growth and bio-fortify cell walls to restrict hyphal spread. Cell wall lignification or thickening occurred in the cortical tissue of the infected R-NIL roots but not in S-NIL roots. As such, high levels of lignin were deposited in exodermal tissues of R-NIL roots (Fig. 7A), whereas lignin was deposited within the vascular cylinder of S-NIL roots (Fig. 7B). These findings strengthen the argument that phenols involved in lignin biosynthesis may slow or halt $F$. graminearum growth.

\section{Transcriptome sequencing reveals} comprehensive transcription reprogramming and the regulation of diverse defense signaling pathways conferred by QTL $q R \boldsymbol{f g} 1$-encoded transcription regulator.

Complex transcription reprogramming has been observed in several pathosystems (e.g., maize-Ustilago maydis and rice [Oryza sativa]-Magnaporthe oryzae) because specific transcription and metabolic changes are often induced by pathogen infection (Doehlemann et al. 2008; Marcel et al. 2010; Mosquera et al. 2009; Torregrosa et al. 2004). To gain insight into the mechanisms of pathogen resistance, the transcriptomes of R-NIL and S-NIL were sequenced. Because the QTL $q R f g l$ encodes a transcription regulator (unpublished data), it is not surprising to observe a large number of DEG that result from $F$. graminearum infection. Expression of most DEG was consistently up- or downregulated during the entire infection process (Fig. 6A and B). In wheat tissues, a large number of transcripts are downregulated upon F. graminearum infection (Golkari et al. 2009).
Similar to the susceptible maize S-NIL, most of its DEG were downregulated during the infection (Fig. 6D). In contrast, most DEG from R-NIL were upregulated after 18 hai (Fig. 6C). The cellular and molecular defense responses were quite different between R-NIL and S-NIL. R-NIL initiated a rapid and intense response whereas that of S-NIL was slow and weak. This agrees with previous assumptions that resistant varieties often exhibit rapid plant-defense responses (Foroud et al. 2012). Moreover, biosynthesis pathways for phenylpropanoids and alkaloids were enriched in the R-NIL transcriptomes (Fig. 6E), consistent with the reports that plant secondary metabolites (e.g., steroidal alkaloids and triterpenes) have antimicrobial activity in vitro (Dixon 2001) and that the indole alkaloid gramine protects against $F$. graminearum in wheat (Schreiber et al. 2011).

Expression levels of $38 \mathrm{TF}$, which involve diverse growth and defense signaling networks, were significantly up- or downregulated during the infection process, revealing complex transcription reprogramming. The superfamily of MYB TF plays roles in diverse developmental processes and defense responses in plants. WRKY TF are primarily found in plants and regulate complex signaling pathways and transcription reprogramming (Dong et al. 2003; Golldack et al. 2011; Pandey and Somssich 2009). The NAC TF regulate secondary cell-wall biosynthesis and associated downstream events (Ohashi-Ito et al. 2010; Yamaguchi et al. 2011). This may relate to the cell-wall thickening that was observed between R-NIL cortical cells.

Plants constantly strike a balance between defense (the robustness of immunity) and growth (the negative effect of immunity on plant fitness) as they adapt to ever-changing environments. Plant hormone signaling plays a role to integrate plant resistance with growth and development. It has been shown that resistance $(R)$ genes are expressed constitutively in living cells at very low levels. They are not required for survival, and their overexpression leads to precocious defense activation and plant cell death (Hammond-Kosack and Kanyuka 2007), and their constitutive activation results in dwarfism (Nandi et al. 2003; Zhang et al. 2010). It is assumed that the expression of $R$ genes and the activation of defense-response pathways are associated with fitness costs. Therefore, fine-tuning the plantdefense response would reduce these associated fitness costs and enhance the effectiveness of defense responses upon pathogen infection (Joshi and Nayak 2011). To guarantee normal growth and development, plants must subtly control defense responses to versatile pathogen challenges. Our results are consistent with these findings, because genes upregulated by $F$. graminearum infection (defense related) were expressed at much lower levels in the R-NIL control (R0) than that in the SNIL control (S0). Similarly, all the downregulated genes (growth related) were expressed at higher levels in the R-NIL control than that in the S-NIL control. Plants that successfully balance the expression of growth- and defense-related genes may be better equipped to exploit available resources and biosynthesize more products (such as phenols) to optimize its growth according to a changing environment. As such, plants likely express growth-related genes at high levels in the absence of pathogen infection but express defense-related genes at high levels upon pathogen challenge. This kind of transcription regulation may contribute to the rapid and intense resistance response that characterizes the maize R-NIL plants. All these results are in agreement with the fact that QTL $q R f g l$ encodes a transcription regulator that exerts pleiotropic effects on plant growth and response to various abiotic stresses (unpublished data). It could be concluded that the QTL $q R f g 1$ confers maize resistance to $F$. graminearum infection through fine-tuning plant growth to reduce the fitness cost and enhance efficiency in defense response upon pathogen infection. 


\section{MATERIALS AND METHODS}

\section{Plant materials.}

A pair of NIL, R-NIL and S-NIL, carrying either resistant or susceptible alleles at the $q R f g 1$ locus, was used in this study. The NIL pair was developed by crossing the resistant donor (1145) to the susceptible receptor (Y331) parent, followed by continuous backcrossing to Y331. Each progeny from every backcross generation was genotyped at the $q R f g l$ locus and inoculated with $F$. graminearum in the field to select those resistant recombinants for the next backcrossing. In an advanced backcross population $\left(\mathrm{BC}_{10}\right)$, individuals with the shortest QTL region were self-pollinated twice to generate the NIL: RNIL with the resistance allele and S-NIL with the susceptible allele at the $q R f g 1$ locus. The introgression size in the NIL from the donor 1145 was validated to be approximately 170 $\mathrm{kb}$, and more than $99 \%$ genetic background was recovered to the recurrent parent Y331.

\section{The $\boldsymbol{F}$. graminearum strain, inoculation, and disease severity scoring.}

The fungal pathogen $F$. graminearum was provided by $\mathrm{X}$. Wang (Chinese Academy of Agricultural Sciences, Beijing). The $F$. graminearum maroconidia were prepared according to Yang and associates (2010) and used for inoculation on primary roots. The maize kernels were soaked in water for $12 \mathrm{~h}$, followed by sterilization and thorough washing, and then incubated in a wet chamber under $16 \mathrm{~h}$ of light and $8 \mathrm{~h}$ of darkness at $26^{\circ} \mathrm{C}$. Three days later, the primary roots (approximately 6 to $8 \mathrm{~cm}$ in length) were inoculated by immersing the roots into a $2 \times 10^{7}$ macroconidia solution and incubated for $1 \mathrm{~h}$ at $26^{\circ} \mathrm{C}$ with $50 \mathrm{rpm}$ rotation. Three replicates were set for each genotype with over 60 plants per replicate. The primary roots with typical symptoms were scored at 48 hai and the disease incidence was calculated by dividing the number of diseased roots to the total number of roots. Standard deviation (SD) analysis was performed between the resistant and susceptible NIL to determine statistical significance.

\section{Determination of the fungal biomass.}

The diseased root fragments (approximately $2 \mathrm{~cm}$ in length) and the nondiseased upper root fragments (approximately $2 \mathrm{~cm}$ in length above the diseased roots) were collected and weighed from 10 primary roots for each of two NIL at 48 hai. The root samples were grounded in $2 \mathrm{ml}$ of $0.5 \%$ Tween 20 solution. The supernatant was diluted to $100 \times, 1,000 \times$, and $10,000 \times$ with sterile water and spread on potato dextrose agar plates. The plates were incubated under $26^{\circ} \mathrm{C}$ for 3 days and the clones grew from single fungal spores were counted. The fungal biomass was obtained with $\log _{10}$ clone-forming units per gram fresh weight of roots. For each of the two NIL, three biological replicates were set and SD was used to determine the statistical significance.

\section{The transgenic $F$. graminearum line with a stably expressing CFP.}

Plasmid pZD101 was used to generate a CFP-tagged transgenic $F$. graminearum strain, which contained the AmCyan (a mutant of cyan fluorescent protein) gene driven by the strong constitutive VM3 promoter, an ampicillin resistance for screening in Escherichia coli, and a hygromycin B $(H y g B)$ resistance for screening in fungi (Zhang et al. 2012). The plasmid was introduced into $F$. graminearum genome by PEG-mediated protoplast transformation method. The transgenic $F$. graminearum lines stably expressing CFP were continuously selected for both $H y g B$ resistance and CFP signal for more than five generations. Single fungal spores characterized with fast growth in in vitro culture, strong fluorescence (under CFP filter), and strong pathogenicity (similar to the wild type) were screened and maintained in glycerol stocks at $-80^{\circ} \mathrm{C}$. Similar pathogenicity of the CFP-tagged transgenic $F$. graminearum strain was further confirmed by counting the percentage of diseased primary roots and comparing disease severity through inoculating the susceptible maize NIL.

\section{Confocal observation of the fungal growth.}

The maize roots 48 hai with the CFP-tagged $F$. graminearum strain were collected and the diseased root segments were transversely free-hand sectioned. The sections were observed under a laser-scanning confocal microscope Zeiss 510 META with 470-nm exciting wavelength and 530-nm emission wavelength. The whole-root transverse images were recorded with a $\times 10$ objective and the detailed cellular fungal distribution was obtained with a $\times 40$ objective. Images were processed with Adobe Photoshop software.

\section{Electronic microscopy observation of the maize roots.}

The different parts of the maize roots 48 hai (the diseased root fragments and the nondiseased upper root fragments) were collected, fixed, and used for all electronic microscopy observations. For transmission electron microscopy observation, the diseased root segment and the nondiseased upper part of the fresh maize root samples 48 hai were treated and done according to Ferguson and associates (1998). For scanning electron microscopy, pieces of maize roots approximately $5 \mathrm{~mm}$ in length were fixed and later treated and observed according to Jin and associates (2011).

\section{RNA sequencing.}

The NIL pair was inoculated with $F$. graminearum conidia, and 10 plants from each NIL were sampled at $0,6,18$, and 48 hai, then immediately frozen in liquid and stored at $-80^{\circ} \mathrm{C}$. This experiment was repeated three times as three biological replicates. Total RNAs were extracted from maize roots at each time-point stage by using Trizol reagent (Invitrogen, Carlsbad, CA, U.S.A.). Poly(A) RNA isolation was done with the Dynabeads mRNA DIRECT Kit (Invitrogen) and performed according to the manufacturer's protocol. A fraction of $100 \mathrm{ng}$ of Poly(A) RNA from each sample was fragmented for RNAseq library construction according the manufacturer's recommendations (Illumina, San Diego, CA, U.S.A.) and sequenced on the Illumina Hiseq2000. Samples from three biological replicates were used for all RNA-seq experiments.

\section{Defining DEG and cluster analysis.}

Clean reads were used for mapping, calculation, and normalization of gene expression. Reads were aligned to the masked maize genome database (AGPv1, release 4a.53, 2009-03-20). Calculation and normalization of gene expression were based on the reads per kilobase per million mapped reads calculation described by Mortazavi and associates (2008). DEG were defined with the FDR $\left(1 \times 10^{-10}\right)$, controlled by the Benjamini and Hochberg procedure (1995). Parameters used for screening the DEG were the fold change (FC) of the expression level (FC $\geq 2$ or $\mathrm{FC} \leq 0.5$ under $P$ value $\leq 0.001$ and $\mathrm{FDR} \leq 0.001$ ), compared with expression level in the control transcriptome. Putative maize homologs were functionally classified using the MapMan functional classification system (Thimm et al. 2004). Cluster analysis was done with the software Cluster 3.0.

\section{Determination of the phenolic acids concentration.}

The standard caffeic acid, p-cumaric acid, ferulic acid, and SA samples were purchased from Sigma-Aldrich (St. Louis). The maize roots were extracted with aqueous acetone $(70 \%$, 
$\mathrm{vol} / \mathrm{vol})$ for $1 \mathrm{~h}$ at ambient temperature three times $(15 \mathrm{ml}$ each). After filtration, the aqueous phase was adjusted to $\mathrm{pH}$ 4.5 and the acetone in the combined extracts was evaporated to dryness in vacuo $\left(280 \mathrm{mbar}, 30^{\circ} \mathrm{C}\right)$. The residue was dissolved in methanol $(0.5 \mathrm{ml})$, membrane filtered $(0.2 \mu \mathrm{m})$, and used for HPLC. The measurement of the phenolic acids by HPLC was done according to Schieber and associates (2001). For each of two NIL, the maize roots were collected at 0,18 , and 48 hai, each with three biological replicates. SD was used for the analysis of the data.

\section{Real-time RT-qPCR validation.}

Real-time RT-qPCR was used to validate the RNA-seq results for those defense-related genes that showed different fold changes in expression level between the resistant and susceptible genotypes. Primers were designed with Primer Express Software, according to standard parameters for real-time RTqPCR assays (Bio-Rad Laboratories, Hercules, CA, U.S.A.).

\section{ACKNOWLEDGMENTS}

This work was financially supported by the National Basic Research '973' program of China, grant number 2009CB118402, and the National High-tech '863' Program of China, grant numbers 2012AA10A306 and 2012AA101104. The funders had no role in study design, data collection and analysis, decision to publish, or preparation of the manuscript.

\section{LITERATURE CITED}

Beccari, G., Covarelli, L., and Nicholson, P. 2011. Infection processes and soft wheat response to root rot and crown rot caused by Fusarium culmorum. Plant Pathol. 60:671-684.

Beckman, C. H. 2000. Phenolic-storing cells: Keys to programmed cell death and periderm formation in wilt disease resistance and in general defence responses in plants? Physiol. Mol. Plant Pathol. 57:101-110.

Benjamini, Y., and Hochberg, Y. 1995. Controlling the false discovery rate: A practical and powerful approach to multiple testing. J. R. Stat. Soc. B 57:289-300.

Bischof, M., Eichmann, R., and Hückelhoven, R. 2011. Pathogenesis-associated transcriptional patterns in Triticeae. J. Plant Physiol. 168:9-19.

Boenisch, M. J., and Schäfer, W. 2011. Fusarium graminearum forms mycotoxin producing infection structures on wheat. BMC Plant Biol. 11:110.

Bollina, V., Kumaraswamy, G. K., Kushalappa, A. C., Choo, T. M., Dion, Y., Rioux, S., Faubert, D., and Hamzehzarghani, H. 2010. Mass spectrometry-based metabolomics application to identify quantitative resistance-related metabolites in barley against Fusarium head blight. Mol. Plant Pathol. 11:769-782.

Brown, N. A., Urban, M., van de Meene, A. M., and Hammond-Kosack, K. E. 2010. The infection biology of Fusarium graminearum: Defining the pathways of spikelet to spikelet colonisation in wheat ears. Fungal Biol. 114:555-571.

Chen, X., Steed, A., Harden, C., and Nicholson, P. 2006. Characterization of Arabidopsis thaliana-Fusarium graminearum interactions and identification of variation in resistance among ecotypes. Mol. Plant Pathol. 7:391-403.

Chen, X., Steed, A., Travella, S., Keller, B., and Nicholson, P. 2009. Fusarium graminearum exploits ethylene signalling to colonize dicotyledonous and monocotyledonous plants. New Phytol. 182:975-983.

Desmond, O. J., Manners, J. M., Stephens, A. E., Maclean, D. J., Schenk, P. M., Gardiner, D. M., Munn, A. L., and Kazan, K. 2008. The Fusarium mycotoxin deoxynivalenol elicits hydrogen peroxide production, programmed cell death and defence responses in wheat. Mol. Plant Pathol. 9:435-445.

Ding, L., Xu, H., Yi, H., Yang, L., Kong, Z., Zhang, L., Xue, S., Jia, H., and Ma, Z. 2011. Resistance to hemi-biotrophic F. graminearum infection is associated with coordinated and ordered expression of diverse defense signaling pathways. PLoS One 6:e19008.

Dixon, R. A. 2001. Natural products and plant disease resistance. Nature 411:483-487.

Doehlemann, G., Wahl, R., Horst, R. J., Voll, L. M., Usadel, B., Poree, F., Stitt, M., Pons-Kühnemann, J., Sonnewald, U., Kahmann, R., and Kämper, J. 2008. Reprogramming a maize plant: Transcriptional and metabolic changes induced by the fungal biotroph Ustilago maydis. Plant J. 56:181-195.
Dong, J., Chen, C., and Chen, Z. 2003. Expression profiles of the Arabidopsis WRKY gene superfamily during plant defense response. Plant Mol. Biol. 51:21-37.

Ferguson, C., Teeri, T. T., Siika-aho, M., Read, S. M., and Bacic, A. 1998. Location of cellulose and callose in pollen tubes and grains of Nicotiana tabacum. Planta 206:452-460.

Ferrari, S., Sella, L., Janni, M., De Lorenzo, G., Favaron, F., and D'Ovidio, R. 2012. Transgenic expression of polygalacturonase-inhibiting proteins in Arabidopsis and wheat increases resistance to the flower pathogen Fusarium graminearum. Plant Biol. 14 (Suppl. 1):31-38.

Foroud, N. A., Ouellet, T., Larochea, A., Oosterveend, B., Jordand, M. C. Ellis, B. E., and Eudes, F. 2012. Differential transcriptome analyses of three wheat genotypes reveal different host response pathways associated with Fusarium head blight and trichothecene resistance. Plant Pathol. 61:296-314.

Gardiner, D. M., Osborne, S., Kazan, K., and Manners, J. M. 2009. Low $\mathrm{pH}$ regulates the production of deoxynivalenol by Fusarium graminearum. Microbiology 155:3149-3156.

Gardiner, S. A., Boddu, J., Berthiller, F., Hametner, C., Stupar, R. M., Adam, G., and Muehlbauer, G. J. 2010. Transcriptome analysis of the barleydeoxynivalenol interaction: Evidence for a role of glutathione in deoxynivalenol detoxification. Mol. Plant-Microbe Interact. 23:962-976.

Golkari, S., Gilbert, J., Ban, T., and Procunier, J. D. 2009. QTL-specific microarray gene expression analysis of wheat resistance to Fusarium head blight in Sumai-3 and two susceptible NILs. Genome 52:409-418.

Golldack, D., King, I. L., and Yang, O. 2011. Plant tolerance to drought and salinity: Stress regulating transcription factors and their functional significance in the cellular transcriptional network. Plant Cell Rep. 30:1383-1391.

Güldener, U., Seong, K. Y., Boddu, J., Cho, S., Trail, F., Xu, J. R., Adam, G., Mewes, H. W., Muehlbauer, G. J., and Kistler, H. C. 2006. Development of a Fusarium graminearum Affymetrix GeneChip for profiling fungal gene expression in vitro and in planta. Fungal Genet. Biol. 43:316-325.

Hammond-Kosack, K. E., and Kanyuka, K. 2007. Resistance genes ( $R$ genes) in plants. Encycle Life Sci. 40:1-21.

Hamzehzarghani, H., Kushalappa, A. C., Dion, Y., Rioux, S., Comeau, A., Yaylayan, V., Marshall, W. D., and Mather, D. E. 2005. Metabolic profiling and factor analysis to discriminate quantitative resistance in wheat cultivars against Fusarium head blight. Physiol. Mol. Plant Pathol. 66:119-133.

Hamzehzarghani, H., Paranidharan, V., Abu-Nada, Y., Kushalappa, A., Dion, Y., Rioux, S., Comeau, A., Yaylayan, V., and Marshall, W. D. 2008. Metabolite profiling coupled with statistical analyses for potential high-throughput screening of quantitative resistance to Fusarium head blight in wheat. Can. J. Plant Pathol. 30:24-36.

Henkes, G.J., Jousset, A., Bonkowski, M., Thorpe, M. R., Scheu, S., Lanoue, A., Schurr, U., and Röse, U. S. 2011. Pseudomonas fluorescens CHO maintains carbon delivery to Fusarium graminearum-infected roots and prevents reduction in biomass of barley shoots through systemic interactions. J. Exp. Bot. 62:4337-4344.

Huffaker, A., Kaplan, F., Vaughan, M. M., Dafoe, N. J., Ni, X., Rocca, J. R., Alborn, H. T., Teal, P. E., and Schmelz, E. A. 2011. Novel acidic sesquiterpenoids constitute a dominant class of pathogen-induced phytoalexins in maize. Plant Physiol. 156:2082-2097.

Jia, H., Cho, S., and Muehlbauer, G. J. 2009. Transcriptome analysis of a wheat near-isogenic line pair carrying Fusarium head blight-resistant and -susceptible alleles. Mol. Plant-Microbe Interact. 22:1366-1378.

Jia, H., Millett, B. P., Cho, S., Bilgic, H., Xu, W. W., Smith, K. P., and Muehlbauer, G. J. 2011. Quantitative trait loci conferring resistance to Fusarium head blight in barley respond differentially to Fusarium graminearum infection. Funct. Integr. Genomics 11:95-102.

Jin, S., Kanagaraj, A., Verma, D., Lange, T., and Daniell, H. 2011. Release of hormones from conjugates: Chloroplast expression of $\beta$-glucosidase results in elevated phytohormone levels associated with significant increase in biomass and protection from aphids or whiteflies conferred by sucrose esters. Plant Physiol. 155:222-235.

Joshi, R. K., and Nayak, S. 2011. Functional characterization and signal transduction ability of nucleotide-binding site-leucine-rich repeat resistance genes in plants. Genet. Mol. Res. 10:2637-2652.

Kang, Z., and Buchenauer, H. 2000. Ultrastructural and immunocytochemical investigation of pathogen development and host responses in resistant and susceptible wheat spikes infected by Fusarium culmorum. Physiol. Mol. Plant Pathol. 57:255-268.

Kazan, K., Gardiner, D. M., and Manners, J. M. 2012. On the trail of a cereal killer: Recent advances in Fusarium graminearum pathogenomics and host resistance. Mol. Plant Pathol. 13:399-413.

Kikot, G. E., Hours, R. A., and Alconada, T. M. 2009. Contribution of cell wall degrading enzymes to pathogenesis of Fusarium graminearum: A review. J. Basic Microbiol. 49:231-241. 
Kumaraswamy, G. K., Bollina, V., Kushalappa, A. C., Choo, T. M., Dion, Y., Rioux, S., Mamer, O., and Faubert, D. 2011. Metabolomics technology to phenotype resistance in barley against Gibberella zeae. Eur. J. Plant Pathol. 130:29-43.

Lanoue, A., Burlat, V., Henkes, G. J., Koch, I., Schurr, U., and Röse, U. S. 2010. De novo biosynthesis of defense root exudates in response to Fusarium attack in barley. New Phytol. 185:577-588.

Lemmens, M., Scholz, U., Berthiller, F., DallAsta, C., Koutnik, A., Schuhmacher, R., Adam, G., Buerstmayr, H., Mesterházy, A., Krska, R., and Ruckenbauer, P. 2005. The ability to detoxify the mycotoxin deoxynivalenol colocalizes with a major quantitative trait locus for Fusarium head blight resistance in wheat. Mol. Plant-Microbe Interact. 18:13181324.

Li, X., Zhang, J. B., Song, B., Li, H. P., Xu, H. Q., Qu, B., Dang, F. J., and Liao, Y. C. 2010. Resistance to Fusarium head blight and seedling blight in wheat is associated with activation of a cytochrome P450 gene. Phytopathology 100:183-191.

Li, Z., Zhou, M., Zhang, Z., Ren, L., Du, L., Zhang, B., Xu, H., and Xin, Z. 2011. Expression of a radish defensin in transgenic wheat confers increased resistance to Fusarium graminearum and Rhizoctonia cerealis. Funct. Integr. Genomics 11:63-70.

Makandar, R., Nalam, V., Chaturvedi, R., Jeannotte, R., Sparks, A. A., and Shah, J. 2010. Involvement of salicylate and jasmonate signaling pathways in Arabidopsis interaction with Fusarium graminearum. Mol. Plant-Microbe Interact. 23:861-870.

Marcel, S., Sawers, R., Oakeley, E., Angliker, H., and Paszkowski, U. 2010. Tissue adapted invasion strategies of the rice blast fungus Magnaporthe oryzae. Plant Cell 22:3177-3187.

McMullen, M., Jones, R., and Gallenberg, D. 1997. Scab of wheat and barley: A re-emerging disease of devastating impact. Plant Dis. 81:13401348.

Mortazavi, A., Williams, B. A., McCue, K., Schaeffer, L., and Wold, B. 2008. Mapping and quantifying mammalian transcriptomes by RNASeq. Nat. Methods 5:621-628,

Mosquera, G., Giraldo, M. C., Khang, C. H., Coughlan, S., and Valent, B. 2009. Interaction transcriptome analysis identifies Magnaporthe oryzae BAS1-4 as biotrophy-associated secreted proteins in rice blast disease. Plant Cell 21:1273-1290.

Nandi, A., Krothapalli, K., Buseman, C. M., Li, M., Welti, R., Enyedi, A., and Shah, J. 2003. Arabidopsis sfd mutants affect plastidic lipid composition and suppress dwarfing, cell death, and the enhanced disease resistance phenotypes resulting from the deficiency of a fatty acid desaturase. Plant Cell 15:2383-2398.

Nicholson, R., and Hammerschmidt, R. 1992. Phenolic compounds and their role in disease resistance. Annu. Rev. Phytopathol. 30:369-389.

Nishiuchi, T., Masuda, D., Nakashita, H., Ichimura, K., Shinozaki, K., Yoshida, S., Kimura, M., Yamaguchi, I., and Yamaguchi, K. 2006. Fusarium phytotoxin trichothecenes have an elicitor-like activity in Arabidopsis thaliana, but the activity differed significantly among their molecular species. Mol. Plant-Microbe Interact. 19:512-520.

Ohashi-Ito, K., Oda, Y., and Fukuda, H. 2010. Arabidopsis VASCULARRELATED NAC-DOMAIN6 directly regulates the genes that govern programmed cell death and secondary wall formation during xylem differentiation. Plant Cell 22:3461-3473.

Pandey, S. P., and Somssich, I. E. 2009. The role of WRKY transcription factors in plant immunity. Plant Physiol. 150:1648-1655.

Parry, D. W., Jenkinson, P., and McLeod, L. 1995. Fusarium ear blight (scab) in small grain cereals-a review. Plant Pathol. 44:207-238.

Pennell, R. I., and Lamb, C. 1997. Programmed cell death in plants. Plant Cell 9:1157-1168

Pestka, J. J. 2010. Deoxynivalenol-induced proinflammatory gene expression: Mechanisms and pathological sequelae. Toxins 2:1300-1317.

Ponts, N., Pinson-Gadais, L., Boutigny, A. L., Barreau, C., and RichardForget, F. 2011. Cinnamic-derived acids significantly affect Fusarium graminearum growth and in vitro synthesis of type B trichothecenes. Phytopathology 101:929-934.

Poppenberger, B., Berthiller, F., Lucyshyn, D., Sieberer, T., Schuhmacher, R., Krska, R., Kuchler, K., Glössl, J., Luschnig, C., and Adam, G. 2003. Detoxification of the Fusarium mycotoxin deoxynivalenol by a UDPglucosyltransferase from Arabidopsis thaliana. J. Biol. Chem. 278:47905-47914.

Pumphrey, M. O., Bernardo, R., and Anderson, J. A. 2007. Validating the Fhb1 QTL for Fusarium head blight resistance in near-isogenic wheat lines developed from breeding populations. Crop Sci. 47:200-206.

Richberg, M. H., Daniel, H. A., and Dangl, J. L. 1998 Dead cells do tell tales. Curr. Opin. Plant Biol. 1:480-485.

Rittenour, W. R., and Harris, S. D. 2010. An in vitro method for the analysis of infection-related morphogenesis in Fusarium graminearum. Mol. Plant Pathol. 11:361-369.

Schieber, A., Keller, P., and Carle, R. 2001. Determination of phenolic acids and flavonoids of apple and pear by high-performance liquid chromatography. J. Chromatogr. A 910:265-273.

Schreiber, K. J., Nasmith, C. G., Allard, G., Singh, J., Subramaniam, R., and Desveaux, D. 2011. Found in translation: High-throughput chemical screening in Arabidopsis thaliana identifies small molecules that reduce Fusarium head blight disease in wheat. Mol. Plant-Microbe Interact. 24:640-648.

Shin, S., Mackintosh, C. A., Lewis, J., Heinen, S. J., Radmer, L., DillMacky, R,, Baldridge, G. D., Zeyen, R. J., and Muehlbauer, G. J. 2008. Transgenic wheat expressing a barley class II chitinase gene has enhanced resistance against Fusarium graminearum. J. Exp. Bot. 59:2371-2378.

Stephens, A. E., Gardiner, D. M., White, R. G., Munn, A. L., and Manners, J. M. 2008. Phases of infection and gene expression of Fusarium graminearum during crown rot disease of wheat. Mol. Plant-Microbe Interact. 21:1571-1581.

Thatcher, L. F., Manners, J. M., and Kazan, K. 2009. Fusarium oxysporum hijacks COI1-mediated jasmonate signaling to promote disease development in Arabidopsis. Plant J. 58:927-939.

Thimm, O., Bläsing, O., Gibon, Y., Nagel, A., Meyer, S., Krüger, P., Selbig, J., Müller, L. A., Rhee, S. Y., and Stitt, M. 2004. MAPMAN: A user-driven tool to display genomics data sets onto diagrams of metabolic pathways and other biological processes. Plant J. 37:914-939.

Torregrosa, C., Cluzet, S., Fournier, J., Huguet, T., Gamas, P., Prosperi, J. M., Esquerre, M. T., Dumas, B., and Jacquet, C. 2004 Cytological, genetic, and molecular analysis to characterize compatible and incompatible interactions between Medicago truncatula and Colletotrichum trifolii. Mol. Plant-Microbe Interact. 17:909-920.

Trail, F. 2009. For blighted waves of grain: Fusarium graminearum in the postgenomics era. Plant Physiol. 149:103-110

Volpi, C., Janni, M., Lionetti, V., Bellincampi, D., Favaron, F., and D'Ovidio, R. 2011. The ectopic expression of a pectin methyl esterase inhibitor increases pectin methyl esterification and limits fungal diseases in wheat. Mol. Plant-Microbe Interact. 24:1012-1019.

Yamaguchi, M., Mitsuda, N., Ohtani, M., Ohme-Takagi, M., Kato, K., and Demura, T. 2011. VASCULAR-RELATED NAC-DOMAIN7 directly regulates the expression of a broad range of genes for xylem vessel formation. Plant J. 66:579-590.

Yang Q., Yin, G. M., Guo, Y. L., Zhang, D. F., Chen, S. J., and Xu, M. L. 2010. A major QTL for resistance to Gibberella stalk rot in maize. Theor. Appl. Genet. 121:673-687.

Zhang, X. W., Jia, L. J., Zhang, Y., Jiang, G., Li, X., Zhang, D., and Tang, W. H. 2012. In planta stage-specific fungal gene profiling elucidates the molecular strategies of Fusarium graminearum growing inside wheat coleoptiles. Plant Cell 24:5159-5176.

Zhang, Y., Yang, Y., Fang, B., Gannon, P., Ding, P., and Li, X. 2010. Arabidopsis snc2-1D activates receptor-like protein-mediated immunity transduced through WRKY70. Plant Cell 22:3153-3163. 